\title{
Chrónos \& Kairós: o tempo nos tempos da escola
}

\author{
Valéria Milena Röhrich Ferreira* \\ Yvelise Freitas de Souza Arco-Verde**
}

\begin{abstract}
RESUMO
O artigo aborda a questão dos tempos escolares. Reflete a respeito da noção de tempo e do modo como esta é constituída histórica e culturalmente. Analisa diferentes formas pelas quais passou e tem passado o tempo escolar, suas diferentes configurações e significados.

Palavras-chave: tempos escolares, jornada escolar, ciclos de aprendizagem.
\end{abstract}

\begin{abstract}
This paper deals with school times. It offers a reflection on timing notion and in both ways it is understood - historically and culturally. It analyses different ways schools have been submitted to and their consequent meanings and configurations.

Key-words: school times, school load, learning cycles.
\end{abstract}

Talvez um dos maiores problemas nas discussões sobre o tempo seja o uso rotineiro de sua noção, a qual oculta grandes questões não resolvidas, que se escondem por trás das inquietações do homem sobre sua origem e sua

* Mestranda em Educação do Programa História, Política, Sociedade da Pontifícia Universidade Católica de São Paulo e Pedagoga da Rede Municipal de Educação de Curitiba e da Rede Estadual de Educação do Paraná.vmilena@ig.com.br

***Professora Adjunto IV do Setor de Educação da Universidade Federal do Paraná. Mestre em Educação na área de Currículo pela Universidade Federal do Paraná. Doutoranda em Educação do Programa História, Política, Sociedade da Pontifícia Universidade Católica de São Paulo. arcoverde@onda.com.br 
finitude. Tanto as dificuldades de reflexão quanto as tentativas de definição do tempo refletem, até hoje, as dúvidas formuladas por SANTO AGOSTINHO (1973, p. 17) "Que é, pois, o tempo? (...) Se ninguém mo perguntar, eu sei; se o quiser explicar a quem me fizer a pergunta, já não sei."

Como a noção de tempo normalmente serve para determinar o antes e o depois de processos muito variados, os homens têm facilmente a impressão de que o tempo existe, independentemente de qualquer seqüência de referência que tenha sido socialmente padronizada, ou de qualquer relação com processos específicos construídos historicamente. Aquilo que a grande maioria das pessoas chama de tempo pode ser indicado como o elemento comum a uma diversidade de processos específicos que os homens procuram marcar com a ajuda de relógios ou calendários.

Segundo ELIAS (1998, p. 84), o "fetichismo do tempo" é reforçado na percepção humana porque sua padronização social inscreve-se na consciência individual, tão mais sólida e profundamente quanto mais a sociedade se torna complexa e diferenciada, levando todos a se perguntarem contínua e incessantemente "Que horas são?" ou "Que dia é hoje?" As investigações sobre o tempo têm sido constantes e muitos estudos modernos, de diversas áreas, têm buscado resgatar nos mitos a análise da história da humanidade, sob diferentes aspectos. A narração mitológica envolve basicamente acontecimentos supostos, relativos a épocas primordiais, ocorridos antes do surgimento dos homens (história dos deuses) ou com os "primeiros" homens (história ancestral). O verdadeiro objeto do mito, contudo, não são os deuses nem os ancestrais, mas a apresentação de um conjunto de ocorrências fabulosas com que se procura dar sentido ao mundo.

Algumas concepções mitológicas sobre o tempo podem exemplificar a complexidade e a variedade das relações de tempo utilizadas pela sociedade. Na mitologia grega, segundo a apresentação de Homero, Zeus substitui, com sua astúcia, Chrónos, ${ }^{1}$ deus do tempo, e passa, assim, a ter um domínio sobre

1 Chrónos, que representa o tempo objetivo, cronológico, contado, aparece na mitologia como o deus grego que representa o tempo, incitado pela mãe e ajudado pelos irmãos, os titãs, castrou o pai (Urano, o céu), separando-o de sua mãe (Géia ou Gé, a terra), e tornou-se o primeiro rei dos deuses. Seu reinado era ameaçado pela profecia segundo a qual um dos seus filhos o destronaria. Chrónos então devorava todos os filhos que lhe dava sua mulher, Réia, até que esta o enganou e salvou Zeus. Este, quando cresceu, arrebatou o trono do pai e o expulsou do Olimpo, banindo-o para o lugar do tormento. Segundo a interpretação clássica, Chrónos simbolizava o tempo e por isso Zeus, ao derrotá-lo, conferira, então, a imortalidade aos deuses. (Enciclopédia Barsa, 1999). 
as questões temporais. O Sol, a Lua e o Dia, bem como a Noite e o Sono ${ }^{2}$ são divindades mitológicas responsáveis pela marcação do tempo, as quais auxiliam na interpretação desses fenômenos da natureza. Esses fenômenos constituem, até hoje, os elementos científicos para a medição do tempo.

A história de Chrónos criada para explicar a suposta evolução cultural da humanidade, em relação ao tempo, é considerada de caráter mítico. Isso indica que o mito constitui uma realidade antropológica fundamental, pois ele não só representa uma explicação sobre as origens do homem e do mundo em que vive, como traduz, por símbolos ricos de significados, o modo como um povo ou civilização entende e interpreta a existência.

Se uma das características fundamentais do pensamento mítico é efetivamente a aceitação acrítica das narrativas e explicações que ele produz, será então extremamente difícil que uma sociedade reconheça seus próprios mitos como tais, pois isso significaria considerá-los de um ponto de vista crítico, de forma que eles passariam a ser identificados como mera ficção ou, se aceitos como verdadeiros, tornar-se-iam valores morais, religiosos ou éticos. Em qualquer caso, existe uma resistência individual e social a "desmascarar" o mito e a considerá-lo em seu caráter de linguagem simbólica.

No entanto, a curiosidade do homem fez com que fossem feitas as distinções entre os deuses e os elementos naturais. O mundo foi submetido ao domínio humano, condição imprescindível para a dominação da natureza. Dominada, o sujeito passa a identificar-se com ela, reduzindo-a e classificando-a como parte de si. Nesse processo, o tempo, enquanto elemento da natureza, passa, então, a ser objetivado, esclarecido.

Com esse esclarecimento o homem foi se apoderando dos processos de medição (relógios, calendários) e tornou-se prisioneiro desse tempo contado. Hoje, parece inacreditável que em alguma época da história humana alguém pudesse ir trabalhar, marcar um encontro, planejar sua vida sem a consciência do tempo, sem a ajuda de um relógio ou de um calendário. Como imaginar que um homem, como nós, só que situado na era primitiva ou nas seguintes, sem os saberes que temos hoje, fosse capaz de ligar os acontecimentos de seu

2 Como divindades siderais, os gregos adotam Sol ou Hélios, que surge todas as manhãs do Oceano para conduzir o carro do sol, puxado por cavalos que expelem fogo pelas narinas. É irmão de Selene, deusa Lua, linda, de braços brancos, com longas asas, que percorre o céu sobre um carro para levar sua plácida luz aos homens. O Dia é anunciado pela deusa Éos, representada conduzindo o carro da luz, guiando os cavalos, com uma tocha na mão. A Noite, criatura primordial, doma os deuses e os homens submetendo-os, com o auxílio do Sono, ao repouso e à vigília.(SISSA; DETIENNE, 1990, p. 60-61) 
cotidiano, como a caça, a noite, a morte, utilizando noções de tempo ou de causalidade mecânica? Os mitos eram suas representações. Até para uma ordenação do mito, há de se imaginar quanto esforço intelectual foi necessário para as sínteses realizadas. Foi dominando a natureza que os mitos foram sendo substituídos. No entanto como afirmam HORKHEIMER e ADORNO (1986, p. 24):

O mito converte-se em esclarecimento, e a natureza em mera objetividade. O preço que os homens pagam pelo aumento de seu poder é a alienação daquilo sobre o que exercem o poder. $\mathrm{O}$ esclarecimento comporta-se com as coisas como o ditador se comporta com os homens. O homem de ciência conhece as coisas na medida em que pode fazê-las. É assim que seu em-si torna-se para-ele. Nesta metamorfose, a essência das coisas revela-se como sempre a mesma, como substrato da dominação.

A desmitologização pelo esclarecimento, com a destruição dos deuses e símbolos, distinguindo-os dos elementos da natureza, fornece ao homem o domínio desta. A natureza, objetivada, segundo HORKHEIMER e ADORNO (1986, p. 25), precisa ser dominada e, nesta dominação, a natureza passa a ser parte do homem, sem diferenciação, produzindo uma nova alienação. $\mathrm{O}$ processo de esclarecimento foi sendo construído pelas necessidades sociais do homem e sua vida comunitária. O homem, tempo, relógio e calendário passaram a se identificar num mesmo processo, perdendo-se a noção da construção do próprio esclarecimento, da separação entre sujeito e natureza.

Segundo ELIAS (1998, p. 99), a noção de tempo utilizada na humanidade até poucos séculos atrás, servia para determinar, de acordo com o antes e o depois, processos variados de experiências sociais. Era a cronologia centrada no homem e suas ações que respondiam às necessidades humanas, a hora da reza, do discurso, da plantação. Neste sentido, o tempo tinha o caráter de uma instituição social, de uma instância reguladora dos acontecimentos sociais, de uma modalidade da experiência humana.

Os homens da sociedade atual, ainda conforme ELIAS, parecem esquecer que a humanidade precisou aprender, sistematizar e dominar o tempo, e eles, agora, necessitam de um processo longo para compreender este complexo simbólico. Uma criança da sociedade industrializada do século XX e submetida a uma regulação temporal muito intensa, leva de sete a nove anos para aprender a dizer as horas, isto é para saber ler e interpretar o complexo siste- 
ma simbólico dos relógios e calendários para adaptar-se a ele, além de ajustar sua sensibilidade e seu comportamento às regras por ele impostas. A regulação direta ou indireta dos dias e das noites, por meio de sinais de valor temporal que se lêem neste ou naquele instrumento, é uma evidência que está fora de dúvidas.

As marcas temporais, entretanto, nem sempre foram as mesmas. Observa-se que o padrão de tempo, após longa caminhada humana, foi sendo modificado, até que o dia solar ${ }^{3}$ passou a ser uma medida universal. Adotou-se, a partir da Assembléia Nacional da França (1789), métodos de medida que, ao tomarem como base as dimensões da Terra, acabaram com as ambigüidades e regionalismos dos sistemas de medidas anteriormente utilizados. Enfim, uniformizou-se o tempo do mundo, padronizou-se o tempo social e os homens foram enquadrados neste mundo temporal.

Apesar de delimitado e medido, as dúvidas sobre o tempo continuam. PRIGOGINE (1988, p. 75), célebre cientista da atualidade, numa conferência proferida em Roma, em 1987, fez reflexões sobre o início do tempo. O físico denunciou que, apesar dos avanços da ciência, ainda há o atraso nas teorias sobre o tempo em relação às implicações das leis das estruturas da física e dos princípios de irreversibilidade, probabilidade e coerência nas medições temporais. Indicou que suspeita-se que o mundo não é feito de movimentos periódicos simples, não é um conjunto de pêndulos. Acrescentou, ainda, em seu discurso: "Não podemos prever o futuro da vida ou do universo... o futuro permanece aberto... o tempo é criação".

Em seu outro livro, Entre o tempo e a eternidade, PRIGOGINE (1992, p. 151) fez seus questionamentos acerca o tempo do universo que, a partir de teorias como a do Big Bang, o raio laser, a biogenética e os avanços da informática e comunicação, tornam possível provar a instabilidade que sucede a uma situação que a precede, enfim, que o universo é resultado de uma mudança de fase em grande escala. Alguns anos mais tarde, no entanto, PRIGOGINE (1996, p. 13) afirmou que, mesmo com as descobertas sobre o ponto de partida e a idade de nosso universo, não há provas sobre o tempo. $\mathrm{O}$ tempo continua sem um início e provavelmente não tem fim.

$3 \mathrm{O}$ dia solar como intervalo entre duas passagens consecutivas do sol pela Terra, foi redefinido até encontrar o segundo solar médio, definido como "1/86.400 do dia solar" e hoje, com a exatidão da ciência moderna, conforme os fundamentos da Física, segundo RAMALHO et al., "um segundo é a duração de 9.192 .631 .770 períodos da radiação correspondente à transição entre os dois níveis hiperfinos do estado fundamental do átomo de césio 133”. (RAMALHO et al., 1998, p. 480) 
Se no campo das ciências exatas o tempo, apesar de instituído, é apontado como flexível e incerto, no campo social e cultural, suas qualidades objetivas bem como seus significados, conforme analisa HARVEY (1992, p. 207218), encontram-se em permanente mudança, de acordo com o modo de produção ou formação social. A mensuração do tempo é um signo do uso do conhecimento para a obtenção de riqueza e poder. Com o advento do capitalismo, os homens que se colocam como definidores das práticas produtivas, das formas de produção, do sentido do dinheiro, fixam, com o uso racional do tempo, certas regras básicas do jogo social. ${ }^{4}$

A eficiência do capitalismo é medida pelo tempo da produção, associado ao tempo de circulação da troca, que produz o tempo de giro do capital. Assim, quanto mais rápida a recuperação do capital posto em circulação, tanto maior é o lucro obtido. Impôs-se, com o capitalismo, a disseminação, na sociedade, do jargão "time is money". Há um incentivo onipresente para a aceleração, por parte dos capitalistas, sobre o tempo de giro do capital, de modo a promover uma tendência social na direção de tempos médios de giro mais rápidos. O trabalhador entra nesse processo complexo de produção articulada com a organização temporal, que traz, na seqüência, a aceleração do ritmo dos processos econômicos e da vida social.

MARX (1983, p. 275) também demonstrou o controle da força de trabalho pela disciplina temporal imposta quando constatou a violenta expropriação dos trabalhadores da Inglaterra Elizabetana, no momento em que o Estado legislou o aumento da duração da jornada de trabalho. ${ }^{5} \mathrm{O}$ trabalhador é obrigado a pautar seu próprio comportamento no tempo instituído pelo sistema de produção e pelo grupo a que pertence. Nesse processo, vive a "ditadura do relógio" e é incapaz de perceber a construção histórica social do tempo.

5 No fordismo, por exemplo, um novo tipo de sociedade deveria ser construída a partir do poder corporativo. Ao definir o dia de trabalho de oito horas a cinco dólares, Ford entendia que o trabalhador adquiria a disciplina, a alta produtividade, mas além disso dava ao trabalhador a renda e o tempo de lazer suficientes para o consumo dos produtos produzidos em massa e as corporações ficavam interessadas em fabricarem quantidades cada vez maiores. (HARVEY, 1992, p. 122)

5 Em O capital e em Teorias da mais-valia, MARX, ao analisar "o valor pelo tempo de trabalho", aponta, nas lutas dos trabalhadores das manufaturas inglesas, para a necessidade da limitação da jornada de trabalho, ao analisar a instauração, na fábrica de New-Lamark, de 10 horas diárias de trabalho. MARX indica a complexidade da lida com a questão temporal, uma vez que as condições de trabalho nas fábricas e a exploração trazem como conseqüência para o operário o embrutecimento do corpo e o esvaziamento nos cérebros. O capitalista usurpa até o tempo livre criado pelo operário para a sociedade. (MARX, 1983, p. 275) 
Neste fim de século, são comuns as manifestações do fim dos tempos, ou do apressar das horas, da aceleração da roda do tempo, talvez pela ilusão mítica de que se chegou ao fim de uma era e de que tudo precise ser retomado. Os relógios que escorrem representados no famoso quadro "Persistência da Memória” (1931), de Salvador Dalí, ilustram bem este sentimento e lembram também o tempo viscoso referido no discurso pós-moderno. Nele, o tempo é tempo exato e tempo solto ao mesmo tempo.

Sobre esta questão, ASSMANN (1998, p. 211) afirma que parte da humanidade já convive com o tempo dos bits exatos, como forma de expressão do dinheiro, das identificações, da escrita, do celular, da internet, da TV digital, do DVD e, contudo, é um tempo no qual todas as fronteiras explodem. Parece que o próprio avanço científico-tecnológico leva a humanidade a navegar, surfar, flutuar.

No desvelamento sobre o tempo, observa-se uma crescente dualidade da noção temporal - o tempo físico e o tempo social. Nesta divisão conceitual, o tempo físico pode ser indicado como aquele que se inicia sob o domínio de Chrónos e determina o ritmo e a contagem do tempo que guia o mundo em dias, horas, minutos etc. e o tempo social - o Kairós, ${ }^{6}$ que pode ser indicado como o tempo vivido pelos homens, nem sempre coincidente com o tempo cronológico. Daí, que seja possível, construir tipologias do mesmo, fazer sua história e analisar suas inter-relações, reconstruir esta complexidade e estratificada estrutura.

A idéia de tempo guarda em si faces contraditórias, tanto de um "tempo intemporal" - abstrato, heterogêneo e infinito - quanto de um "tempo temporal" - concreto, homogêneo, contínuo e regular. O tempo pode ser definido também como único e singular ou múltiplo e plural.

Há os tempos individuais e coletivos, como também os "tempos cíclicos", por exemplo, da infância, do trabalho, da velhice, do lazer. Há os tempos institucionalizados e, dentre estes, encontra-se o tempo escolar.

Pensar em tempo escolar implica em defini-lo em sua especificidade, em um tempo adjetivo, diferente de outros tempos.

Da mesma forma que a estruturação dada ao tempo na história da humanidade, o tempo escolar passou por diferentes configurações e significados e,

6 No grego bíblico, há distinção nítida entre Chrónos e Kairós, em que Káiros significaria: tempo do Dom, hora da graça, da salvação; tempo propício, dia da libertação; hora da "visitação"; momento em que "o anjo passa"; dia do Senhor; shabat; jubileu. Kairós representa o tempo subjetivo, vivencial. A junção de Chrónos e Kairós é traduzida pelo poema bíblico: Tudo tem o seu tempo. (ASSMAN, 1998, p. 213) 
ainda apresenta, nos dias de hoje, uma arquitetura específica e diferenciada não só em sua estrutura institucional, nos diferentes países, estados, cidades e escolas, como na efetivação deste tempo no âmago das práticas pedagógicas. O tempo escolar, além de trazer as marcas da sociedade, é um elemento próprio dessa cultura que constitui o núcleo central das "caixas pretas" da educação.

VIÑAO FRAGO (1998a, p. 174) afirma que esta cultura escolar é institucional e institucionalizada. Diz ele que a cultura escolar se produz no seio de instituições docentes e de um sistema educativo, e é esta interação entre o institucional, o organizativo e o cultural que precisa ser intensificada nos estudos (estaria aqui o desvelamento da "caixa-preta").

O tempo escolar é institucional, é organizativo e é fato cultural. Como tal, resulta de uma construção histórica. As principais características do tempo escolar, a sua organização, sua estrutura e suas práticas nos diferentes sistemas de ensino, implicam em diferentes definições sobre a arquitetura temporal da educação, as quais foram forjadas ao longo de muitos séculos.

A visão da prática educativa, da instituição escolar e da organização pedagógica e temporal deste espaço vem sendo permeada por subordinações à ciência e à tecnologia, recheada de fetichismo em relação às imposições civilizatórias na história da formação social do homem.

A idéia de curso escolar, com seu princípio e fim, ou a da semana como unidade temporal da distribuição no tempo de conteúdos, matérias e atividades, isto é, de uma distribuição diferenciada para todos os dias da semana, vai surgindo aos poucos nas sociedades urbanas, evidenciando um amplo debate educacional. Nesses debates, a discussão sobre o tempo está ligada aos preceitos sociais e religiosos, às exigências morais e civilizatórias, a um novo comportamento social da era moderna, às exigências do mundo industrializado e, ainda, às questões internas à escola, como o cumprimento das listagens de conhecimentos necessários à formação da criança e do jovem.

Um dos debates ocorre no interior de um movimento social de racionalização do tempo, próprio das sociedades modernas, urbanas e industrializadas, que se estabeleceu neste último século. Essa nova mentalidade racionalizadora refletiu a composição de um vocabulário pedagógico com os termos: método, ordem, sistema, mecanismo, engrenagem, técnica e método. O controle do tempo, com a distribuição diária das disciplinas pelo período de algumas horas em que o aluno passasse na escola, impôs uma nova ordem com uma lógica pré-determinada, cronometrada, com um tempo artificial, apropriado e ordenado pela razão humana.

Dada a premência de escolarização para o desenvolvimento industrial e, portanto, a necessidade de dar acesso a uma escolaridade básica para a 
maior parte da população, e pela pressão da burguesia que emergia nos centros urbanos, escolas foram sendo construídas e, para dar vazão à demanda e às necessidades sociais e culturais, foram sendo instituídos na escola jornadas distintas, contínuas ou não, com turnos de 2, 3 ou 4 horas de atividades diárias.

Uma outra vertente do debate sobre o tempo escolar está ligada às necessidades biológicas, respeitando os princípios da Higiene e Saúde. O higienismo - que também pretendia a cientificidade e racionalidade do tempo e do trabalho - discutia aspectos que levassem em conta o esforço, a fadiga e o bem-estar da criança, bem como as condições climáticas e o ambiente escolar. Apontava-se para soluções que alterariam a configuração temporal das escolas como: a introdução de férias, recreios, intervalos, como também a inclusão de exercícios corporais e uma grade curricular que se apresentasse como conveniente ao rendimento do aluno.

Já os debates do movimento da Escola Nova, com suas idéias sobre o respeito, a liberdade e a espontaneidade da criança resistiam em oferecer quadros horários rígidos, tendo como princípio básico que a escola e seus horários estavam feitos para a criança e não ao contrário. Propunha-se para tanto a substituição de uma organização rígida, por outras técnicas, métodos e ordenações curriculares mais flexíveis, formando inclusive novas composições temporais.

As discussões pedagógicas também foram reforçando dois aspectos determinantes da distribuição do tempo como, de um lado, a modificação do leque de conhecimentos a serem ofertados que implicaram numa revisão, ampliação e ordenamento das disciplinas e, de outro, a utilização de métodos de ensino que exigiam dinâmicas diferentes como é o caso dos métodos individual, mútuo e simultâneo, ${ }^{7}$ que implicam em articular o atendimento individual ou coletivo, em tarefas diferenciadas ou grupais.

$\mathrm{O}$ estudo de diferentes realidades educacionais vem nos mostrar a diversidade da distribuição desses tempos nas escolas. Quer decidido pelas im-

7 Segundo FARIA FILHO e VIDAL (2000), o método individual se constituiu com um professor ensinando cada aluno individualmente em uma classe formada por vários alunos. A introdução do método mútuo, indicava a presença de um único professor que poderia dar aulas até para 1000 alunos, contando com o apoio de alunos-monitores, espaço e materiais adequados. O ensino simultâneo, por sua vez, ou seja a utilização do método misto, podia ser reconhecido como as classes de alunos, divididas segundo um mesmo nível de conhecimentos e idade dos alunos, entregues a uma professora que propõe tarefas coletivas, para as quais cada um, e todos os alunos, devem executar uma mesma atividade a um só tempo. (FARIA FILHO; VIDAL, 2000, p. 21-23) 
posições do mundo moderno, capitalista, urbano-industrial, por questões científicas, de higienistas ou escolanovistas, quer por decisões governamentais e administrativas externas à escola, ligadas às decisões político-econômicas ou pelas próprias variáveis internas de organização da escola, é certo que o tempo escolar sempre foi diverso e plural.

No Brasil, o tema do tempo da jornada escolar para o ensino fundamental, por exemplo, na maioria dos estados e municípios, se for estabelecida uma média, prevalece no sentido de atender dois turnos, num total que varia de 150 a 180 dias letivos, seguindo a legislação até 1996. No entanto, dada a carência de vagas e a pressão pelo atendimento à demanda, é comum encontrar, ainda nessa década, escolas que atendem em três, quatro ou até cinco turnos diários, com até aproximadamente duas horas de atendimento por dia. Muitas críticas a estas políticas vêm ocorrendo. Contraditoriamente à redução da jornada e, especialmente a partir da década de 80 , surgem programas de extensão da carga horária para o atendimento integral, de jornada contínua, de um só turno, como as experiências dos CIEPs, Profic, Projeto Curumim, ETIs, CEIs, CIACs e CAICs. ${ }^{8}$ Por meio de projetos e programas específicos, o poder público vem adotando políticas educacionais que, alargam e reduzem o tempo escolar de atendimento às crianças e aos adolescentes, especialmente para aqueles tidos como em situação de risco.

A atual configuração legal do tempo escolar pela Lei de Diretrizes e Bases da Educação Nacional (LDB), aprovada em 1996, torna obrigatório o cumprimento das 800 horas efetivas de aulas por ano, 200 dias letivos, estendendo assim, após muitos embates e discussões, em mais 80 horas, correspondentes a mais 20 dias, a duração do ano letivo. Acrescenta, ainda, um artigo cuja intenção indica que "serão conjugados todos os esforços objetivando a progressão das redes públicas urbanas de ensino fundamental para o regime de escolas de tempo integral" (BRASIL, 1996, Lei 9394/96, art. 87, § 5º IX).

8 Desde a década de 80, inspirados nas idéias e concretizações de Anísio Teixeira, sobre escola de tempo integral, tendo como modelo a Escola Parque da Bahia, são implantados programas e projetos especiais de atendimento aos alunos em tempo integral, como o Centro Integrado de Educação Pública - CIEP, no Rio de Janeiro, o Programa de Formação Integral à Criança - Profic, em São Paulo, a Escola de Tempo Integral - ETI, em Curitiba, o Projeto Curumim, em Minas Gerais, o Centro de Educação Integral - CEI, em Curitiba, o Centro Integrado de Apoio à Criança - CIAC, convertidos em Centro de Atenção Integral à Criança e ao Adolescente - CAIC, em nível nacional, bem como outros programas em diferentes municípios e estados do Brasil, todos com o objetivo de dar assistência ampla à infância, além da escolarização fundamental. 
A polêmica sobre a extensão da jornada continua viva no Brasil. Muitos professores alegam a necessidade de mais tempo para o desenvolvimento de conteúdos. Muitos pais reivindicam um atendimento ampliado, outros criticam a obrigatoriedade de uma jornada tão ampla. Na atual versão, ainda não aprovada, do Plano Nacional de Educação, anuncia-se a intenção de eliminar a existência nas escolas, de mais de dois turnos diurnos e um turno noturno e de ampliar a jornada escolar visando expandir a escola de tempo integral, que abranja um período de pelo menos sete horas diárias. A polêmica, com certeza, continua.

As justificativas apontadas para os programas de extensão da jornada escolar, normalmente estão vinculadas aos discursos de democratização que se voltam ao atendimento dos principais problemas da realidade social e econômica do país. Apontam para a necessidade de assistir crianças em condições de extrema pobreza, pelos graves problemas da violência, acrescido pela falta de espaços sociais e de um atendimento familiar pela necessidade de trabalho dos pais, alegam a possibilidade de um atendimento educacional de qualidade, no enfrentamento das questões de abandono, reprovação e baixa produtividade do sistema escolar.

Por outro lado, as reduções de jornada (para mais de dois turnos de atendimento) são apontadas como medidas extremas, precárias e provisórias para solucionar problemas de falta de vagas para a garantia da obrigatoriedade escolar.

Já a redução da jornada das escolas ou centros de atendimento integral (de jornada única, com um só turno, para dois turnos), como a ocorrida com os CIEPs, no Rio de Janeiro, é justificada pelos altos custos desse atendimento e pela falta de possibilidade de universalização do atendimento integral a todas as crianças da escola pública. Essas avaliações são evidentemente realizadas por facções políticas diferentes das que idealizaram e implantaram a proposta.

O certo é que professores, alunos e a própria sociedade têm se tornado reféns dessas políticas estruturais do sistema de ensino, assim como de propostas que interferem diretamente na prática educacional, no trabalho direto de sala de aula com os alunos, conforme se verá a seguir.

Com a institucionalização da escola e o avanço tanto de teorias educacionais como de outras ciências que dão suporte ao trabalho pedagógico, mais questões se põem em relação aos tempos escolares, especialmente com as propostas de novos métodos que levem em conta as características do aluno, respeitando o seu tempo de aprendizagem.

Discussões sobre a improdutividade do sistema educacional, com seus 
altos índices de fracasso, ${ }^{9}$ desistências, baixa qualidade do ensino e altos gastos com a educação, são pautas discutidas desde o início do século, no Brasil. Já nas suas primeiras décadas propõe-se a "promoção automática" (1919), a "promoção em massa" (1921) e a "promoção por idade" (1954) $)^{10}$ como medidas para solucionar os graves problemas enfrentados. Recomendava-se a urgência de tais políticas para a universalização das oportunidades de acesso e permanência do aluno na escola, garantindo-lhe aprendizagem efetiva e de qualidade. Nessa época, já se fazem críticas a essas formas de promoção, como também pede-se cautela na implantação de tais políticas que deveriam preparar com antecedência o "espírito" do professorado, a fim de obter sua adesão e precaver-se adotando medidas preliminares, sem as quais não se lograria avançar no processo. ${ }^{11}$

O desafio essencial permanece nos debates educacionais seguintes, acrescentando-se, ainda, questões ligadas às necessidades sociais e a atenção aos interesses e características da criança, uma vez que percebe-se que o tempo estabelecido pelo sistema ou escola quase nunca coincide com o tempo de aprendizagem dos alunos.

Assim, na década de 80, em pleno movimento de democratização da educação no país, novamente retoma-se a discussão e diversas Secretarias de Educação, como também organismos e entidades de ensino e pesquisa, empenhados na reorganização da escola pública, apontam como solução para a evasão e repetência, a flexibilização do tempo e do espaço escolares. Questionam a segmentação artificial do currículo em séries, tratadas de modo estanque, com alunos que, tendo avançado no processo de alfabetização ao longo da $1 .{ }^{\mathrm{a}}$ série, são obrigados a retornar à estaca zero com a repetência, num flagrante desrespeito da escola pelo que já aprenderam. (BARRETTO; MITRULIS, 1999, p. 37)

São Paulo, Minas Gerais e Paraná, a começar do primeiro, são estados que, a partir de 1980, encampam a idéia de dar nova ótica para a organização escolar, abandonando a reprovação e a seriação, e propondo ciclos de aprendizagem. As justificativas para uma mudança de organização temporal defendem que se o educando tivesse maior tempo para alfabetizar-se, não seria

9 O problema da repetência é recorrente na educação brasileira, tendo seu índice oscilando entre $60 \%$ e 50\% nas estatísticas educacionais referentes à passagem da $1 .{ }^{a}$ para a $2 .^{a}$ série do ensino fundamental durante 40 anos: de 1940 a 1980. (BARRETO; MITRULIS, 1999, p. 28)

10 Ibid., p. 29.

11 Recomendações de ALMEIDA JÚNIOR em Congresso de 1956 sobre: "Repetência ou promoção automática?” (BARRETO; MITRULIS, 1999, p. 30) 
reprovado ou não se evadiria da escola. "Alargar" o tempo de alfabetização, redefinir conteúdos e metodologias, modificar a prática, incluir períodos de recuperação inclusive no contraturno, para obter avanço cognitivo do aluno, são medidas também apontadas como necessárias.

Na década de 90, as defesas de um ensino por ciclos continuam e são apontadas também como solução para os problemas escolares pela própria LDB n ${ }^{\circ} 9394 / 96$, em seu artigo $32, \S 1^{\circ}$ e $2^{\circ}$, que facultou aos diversos sistemas educacionais a instituição de ciclos para o Ensino Fundamental, demonstrando uma avaliação satisfatória das propostas regionais implantadas de forma isolada.

No entanto, estudos recentes têm apontado para as deficiências na implantação dos ciclos nas últimas décadas, como: o descaso e descompromisso político, a alta rotatividade e desmotivação dos professores, as insuficientes intervenções pedagógicas na escola, os registros de baixa qualidade do ensino, ou ainda as resistências da própria cultura escolar.

A complexidade da mudança do tempo serial para ciclo recai sobre uma cultura temporal consolidada por uma outra lógica, lógica esta incorporada na cultura escolar há mais de um século e que compreende o ensino seriado como a única organização possível. Escolas, técnicos educacionais, professores, pais e os próprios alunos convivem com estas contradições das lógicas temporais.

Embora legalizadas e implantadas tanto as propostas que organizam o ensino por ciclos, como as de extensão da jornada escolar, sabe-se que o enfrentamento de novos tempos e de novas práticas no âmbito das escolas não se dá de forma linear. Não há desdobramentos mecânicos, previsíveis, que possam ser resumidos em aceitar ou não as reformas educacionais. Existe uma cultura escolar construída que não se destrói, pelo menos imediatamente, com a regulamentação e implantação das políticas públicas. Os profissionais de educação têm explícita ou implicitamente suas crenças e opiniões, além de estarem sujeitos às pressões das instituições políticas, sociais e da própria instituição escolar e seus mecanismos de coerção.

Todos estes elementos indicam que na escola se instalou um processo onde as antigas estruturas de organização escolar e do trabalho docente convivem com as mais recentes. Essa convivência, no entanto, sugere conflitos que se expressam através da continuidade de algumas práticas já consolidadas, da acomodação e da implantação de outras.

Segundo SACRISTAN (1999, p. 88), políticas retóricas que pretendem mudar a cultura pedagógica com slogans simbólicos e com estratégias superficiais fazem com que a prática escolar torne-se invulnerável e impermeável 
a estas políticas de inovação.

Porém, esta mesma cultura escolar não é nem simples reprodutora de políticas, nem refratária às mudanças. A escola tem sua própria identidade, conta com espaços para discussões e reelaborará as idéias dessas políticas de inovação. Essa reelaboração se faz de acordo com suas vivências, com a caminhada que já tem, utilizando o que os professores trazem de sua formação, de suas necessidades e possibilidades, enfim, lançando mão do que tem a sua volta, fazendo, como no dizer de LÉVI-STRAUSS, uma "bricolage"(apud PERRENOUD, 1993, p. 47) entre o que lê, o que escuta, o que assiste em cursos, o que já sabe, o que acredita ideologicamente etc.

Dar, porém, uma nova lógica formal ao tempo escolar consolidado tem evidenciado que não se alteram tão facilmente práticas incorporadas e hábitos profissionais. A prática pedagógica na sala de aula não é a concretização de uma teoria, nem mesmo de regras de ação ou receitas.(PERRENOUD, 1993, p. 40) Ainda, segundo PERRENOUD, determinados comportamentos e atitudes dos professores em variadas situações da prática são condicionados por hábitos individuais, ações repetitivas e mecânicas, resultantes da vivência de rotinas anteriores. Nessas situações da prática, a atuação dos professores é dirigida pelo habitus, ${ }^{12}$ conceito utilizado por BOURDIEU (apud PERRENOUD, 1993, p. 39) para expressar um conjunto de esquemas que permite conceber uma infinidade de práticas adaptadas a situações sempre renovadas sem nunca se constituir em princípios explícitos.

Passar do tempo institucional e social contado (Chrónos) na escola para o tempo do aluno (Kairós) gera uma nova ordem, que não é o ordenamento aprendido e apreendido pela maioria dos educadores, no entanto, conforme foi indicado, há um espaço na escola para que se possa modificar hábitos arraigados, rever tempos e práticas em uma nova organização temporal.

Ao contrário, se é possível aceitar que o homem dominou o tempo e o tempo o dominou, devemos afirmar que Chrónos se transformou em ciência e aprisionou Kairós no seu processo civilizatório? Estaria a escola irremedi-

12 BOURDIEU já apontava para esta questão afirmando que o habitus consiste em “....sistema de disposições duradouras e transferíveis, estruturas predispostas a funcionarem como estruturantes, ou seja, como princípios geradores e organizadores de práticas e de representações que podem estar objetivamente adaptadas ao seu fim, sem supor a busca consciente de fins e o domínio expresso das operações necessárias para alcançá-los, objetivamente 'reguladas' e 'regulares', sem ser o produto da obediência a regras e, ao mesmo tempo, coletivamente orquestradas sem ser produto da ação organizadora de um diretor de orquestra." (BOURDIEU, 1975, p. 92) 
avelmente presa aos tempos que lhe são dados? Estão os tempos cronológicos da escola escravizando as práticas cotidianas? As novas formas de contar os tempos na escola (ciclando, acelerando, aumentando ou diminuindo) estão levando em conta os tempos vividos (por alunos, professores, equipes pedagógicas), ou novamente, e mesmo a seu pretexto, estão enredando-se em apenas mais um tempo formal, burocrático e administrativo?

ADORNO (1995, p. 122) alertou para o perigo da inversão dos meios pelos fins, especialmente no mundo moderno que produz pessoas tecnológicas. Os meios são fetichizados, porque os fins, que representam a vida humana digna, encontram-se encobertos e desconectados da consciência das pessoas.

Nesse sentido, parece fundamental indagar: se o tempo contado pela "inquestionável ciência exata" é hoje questionável, relembrando que PRIGOGINE anuncia que "o tempo é criação", poderia a escola ousar romper as amarras do tempo e redimensionar sua prática? Parece-nos que o futuro da escola e de seus tempos permanece aberto...

\section{REFERÊNCIAS}

ADORNO, T. W. Educação e emancipação. Tradução: Wolfgang Leo Maar. São Paulo: Paz e Terra. 1995. 190 p.

ASSMANN, H. Reencantar a educação: rumo à sociedade aprendente. 2. ed. Petrópolis: Vozes, 1998. 251 p.

BARRETO, E. S. S.; MITRULIS, E. Os ciclos escolares: elementos de uma trajetória. Cadernos de Pesquisa, São Paulo: Autores Associados, n.108, p.2747, 1999. Fundação Carlos Chagas.

BOURDIEU, P.; PASSERON, J. C. A reprodução: elementos para uma teoria do sistema de ensino. 3. ed. Rio de Janeiro: Francisco Alves, 1975. 238 p.

BRASIL. Lei n. 9394, de 20 de dezembro de 1996. Estabelece as diretrizes e bases da educação nacional. Diário Oficial da República Federativa do Brasil, Brasília, p. 27.833, 23 dez. 1996. Seção 1.

CHRÓNOS. In: Enciclopédia Barsa. Rio de Janeiro: ENCYCLOPAEDIA BRITTANNICA, 1999. 1 CD ROM.

ELIAS, N. Sobre o tempo. Tradução: Vera Ribeiro. Rio de Janeiro: Zahar, 1998. $165 \mathrm{p}$. 
FARIA FILHO, L. M.; VIDAL, D. G. Os tempos e os espaços escolares no processo de institucionalização da escola primária no Brasil. Revista Brasileira de Educação, São Paulo, n. 14, p. 19-34, maio-ago. 2000. Número especial.

HARVEY, D. A condição pós-moderna: uma pesquisa sobre as origens da mudança cultural. Tradução Adail Ubirajara Sobral e Maria Stela Gonçalves. São Paulo: Loyola, 1992. 349 p.

HORKHEIMER, M.; ADORNO, T. W. Dialética do esclarecimento: fragmentos filosóficos. Tradução Guido Antonio de Almeida. Rio de Janeiro: Zahar, 1986. 254 p.

MARX, K. O capital. São Paulo: Abril Cultural, 1983. v. 1, t. 1.

PERRENOUD, P. Práticas pedagógicas, profissão docente e formação: perspectivas sociológicas. Lisboa: Nova Enciclopédia, 1993. 201 p.

PRIGOGINE, I. Entre o tempo e a eternidade. São Paulo: Cia. das Letras, 1992. $226 \mathrm{p}$.

. O fim das certezas: tempo, caos e as leis da natureza. São Paulo: Ed. da Universidade Paulista, 1996. 199 p.

. O nascimento do tempo. Lisboa, Portugal: Edições 70, 1988. 92 p.

RAMALHO JUNIOR, F.; FERRARO, N. G.; SOARES, P. A. T. Os fundamentos da Física: Mecânica. 6. ed. São Paulo: Moderna, 1998. v. 1, 480 p.

SACRISTAN, J. G. Poderes instáveis em educação. Porto Alegre: Artes Médicas Sul, 1999. 287 p.

SANTO AGOStinho. Confissões. Trad.: J. O. Santos e A. A. Pina. São Paulo: Abril, 1973. (Os pensadores, Livro XI,14[17]).

SAVIANI, D. Da nova LDB ao novo Plano Nacional de Educação: por uma outra política educacional. Campinas: Autores Associados, 1998.

SISSA, G.; DETIENNE, M. Os deuses gregos. São Paulo: Companhia das Letras, 1990. $317 \mathrm{p}$.

VIÑAO FRAGO, A. L'espace et le temps scolaires comme objet d'histoire. Paris: Institut National de Recherche Pédagogique, Service d'histoire de l'educacion, 1998b. p. 89-108. (Histoire de L'Education, 78).

. Tiempos escolares, tiempos sociales: la distribución del tiempo y del trabajo en la enseñanza primaria en Espanha (1838-1936). Tradução livre: Yvelise F. S. Arco-Verde. Barcelona, Espanha: Editorial Ariel, 1998a. 153 p. 